\title{
APRENDENDO MATEMÁTICA DE FORMA DIFERENTE
}

\author{
FAGUNDES, Dulce Gomes ${ }^{1}$; \\ TEIXEIRA, Tânia Regina²; \\ RIBEIRO, Elizete Maria Possamai ${ }^{3}$; \\ MEDEIROS, Margarete Farias ${ }^{4}$; \\ MORAIS, Ana Maria ${ }^{5}$; \\ CARDOSO, Marleide Coan ${ }^{6}$.
}

\section{INTRODUÇÃO}

O projeto "Escolinha da Matemática" procura trabalhar a Matemática de forma diferente da sala de aula, com os alunos do Ensino Fundamental da rede municipal de Sombrio (SC). Sabe-se que a Matemática é uma das disciplinas em que os alunos do Ensino Fundamental apresentam maiores dificuldades e que, no dia a dia da sala de aula, o professor não possui tempo suficiente para revisões de conteúdo, até mesmo porque cada aluno possui dificuldades em conteúdos diferentes.

As dificuldades da aprendizagem têm sido um problema constante nas salas de aula, por diversas razões, tais como o grande número de alunos e as diferenças de cultura e socialização de cada aluno. Os principais objetivos do projeto foram oportunizar aos alunos revisões em conceitos matemáticos estudados, superando suas dificuldades, mostrando-Ihes que a Matemática é uma ciência presente em seu cotidiano e em tudo que está a sua volta.

Proporcionar aulas de reforço escolar e auxiliar na superação de suas dificuldades por meio do desenvolvimento de metodologias alternativas, como, por exemplo, o uso de jogos, materiais manipulativos e software para o ensino da Matemática. Assim, procurou-se mostrar que a Matemática é uma ciência presente no cotidiano do aluno e de extrema importância para a compreensão do mundo a sua volta, como também contribuir, por meio do ensino da Matemática, para a

\footnotetext{
Instituto Federal Catarinense Campus Avançado Sombrio, dulcegomes.f@outlook.com Instituto Federal Catarinense Campus Avançado Sombrio, taniateixeiraregina@outlook.com Instituto Federal Catarinense Campus Avançado Sombrio, elizete@ifc-sombrio.edu.br Instituto Federal Catarinense Campus Avançado Sombrio, margarete.farias@ifc-sombrio.edu.br Instituto Federal Catarinense Campus Avançado Sombrio, ana.moraes@sombrio.ifc.edu.br Instituto Federal de Santa Catarina Campus Criciúma, marleidecoan.cardoso@gmail.com
} 
melhoria do IDEB (Índice de Desenvolvimento da Educação Básica) das escolas municipais de Sombrio (SC).

\section{MATERIAL E MÉTODOS}

Partindo-se do pressuposto de que os alunos necessitam de um ensino diferenciado para compreender algumas situações matemáticas do cotidiano, foram utilizadas algumas metodologias distintas daquelas utilizadas no dia a dia da sala de aula, visto que, na maior parte do tempo, o professor se utiliza de aula expositiva e dialogada, com exercícios expostos no quadro. Foram aplicadas gincanas em grupo, jogos, uso de materiais concretos, dominós e jogo da memória como estratégias para facilitar o entendimento e a aprendizagem dos conteúdos pelos alunos participantes. Também fez parte deste projeto a discussão de temas transversais, tais como o respeito aos idosos, às pessoas portadoras de necessidades especiais, a importância da família e o respeito ao meio ambiente, por meio de vídeos educativos relacionados com os temas. As atividades com vídeos foram apresentadas em dois momentos: primeiro foi discutido o tema abordado e, em seguida, os alunos descreveram e desenharam os temas propostos.

No decorrer do ano foi possível realizar os jogos por meio das dinâmicas, como mostra-se nas alíneas seguir:

a) Trilha das Equações: A turma foi dividida em grupos de três e quatro alunos. A trilha era composta pelas cores verde, vermelha, azul e amarela. Para iniciar o jogo, cada aluno escolhia uma cor de botão, e em seguida um aluno jogava o dado. O número em que caísse o dado era o número de casas que ele teria que andar na trilha. A cor da casa que ele parava indicava a cor do cartão que ele iria tirar do saquinho. Cada cartão possuía uma equação para resolver, porém no lugar de " $x$ " ela tinha um desenho que representava o valor a ser descoberto.

b) Construção de Polígonos: Consiste em uma representação de polígonos feita por meio do uso de transferidor e régua. Cada aluno fazia uma conta de divisão para saber o ângulo do polígono que desejava. Para fazer um pentágono, o aluno pegava $0360^{\circ}$ do transferidor e dividia por 5 . O resultado obtido foi $72^{\circ}$. A cada $72^{\circ} \circ$ aluno ia marcando um ponto no transferidor. Em seguida, com o auxílio de uma régua, ligava os pontos que formavam o pentágono. 
c) Conhecendo algumas ferramentas do GeoGebra ${ }^{7}$ : Ao iniciar o GeoGebra, os alunos faziam a atividade de marcar os pontos $\mathrm{P}(\mathrm{x}, \mathrm{y})$ indicados pelo exercícios de plano cartesiano e em seguida utilizavam a ferramenta polígono para ir ligando os pontos fechando o polígono, de acordo com a definição dada. Para finalizar o polígono representado, cada aluno escolhia uma cor para pintar o seu polígono.

d) Construção da maquete do campo de futebol: Para realizar a atividade de área e perímetro, os alunos construíram uma maquete de um campo de futebol com o intuito de calcular o perímetro e a área das regiões da pequena e grande área do campo.

e) Gincana de Revisão: Realizou-se uma gincana para a revisão dos conteúdos estudados. A turma foi dividida em dois grupos e cada grupo tirava um papel com atividades para o outro grupo resolver. Após resolver, o grupo que tirava o papel ia até o quadro para corrigir. Se estivesse certo, o ponto iria para o que resolveu; se estivesse errado, o ponto iria para o que corrigiu. $O$ grupo que perdeu sabia resolver, porém estava apressado e desatento, e acabou errando o resultado final.

\section{RESULTADOS E DISCUSSÃO}

Foi possível observar, no decorrer do projeto, que os alunos apresentaram interesse e comprometimento nas aulas, participaram com ênfase e estabeleceram relações entre o que aprendem na escola e o que thes foi ensinado no projeto. Pôde-se observar que a porcentagem dos alunos que compreenderam melhor o conteúdo com o uso de material manipulativo foi muito maior do que com o uso de resoluções de problemas.

Segundo Luckesi (2015), o reforço escolar deve ser utilizado quando necessário. Para o educador, o reforço é uma solução e deve ser utilizado quando necessário, levando em conta que o mais importante mesmo é o aprendizado e não as notas do aluno. Para Silva (2009), o reforço escolar tem por objetivo a aprendizagem dos educandos em nível de desigualdade com o ritmo da turma, consolidando, ampliando os conhecimentos e enriquecendo as experiências

\footnotetext{
${ }^{7}$ GeoGebra é um software livre com recursos para trabalhar a álgebra, geometria plana e espacial, além de outros conceitos matemáticos.
} 
culturais e sociais, para assim ajudá-los a vencer os obstáculos presentes em sua aprendizagem.

Ao finalizar o projeto, fez-se um debate com os alunos para verificar a percepção destes em relação à importância da realização do projeto "Escolinha da Matemática". É importante que haja esse diálogo para buscar respostas para as dificuldades que surgem. Segundo Ruiz e Gomes (1998), na concepção piagetiana, aprender Matemática é adquirir ferramentas cognitivas. Assim,

[..] faz-se necessário que a Educação Matemática não seja interpretada como sinônimo de ensino de matemática, mas como uma área de conhecimentos, em que o educador e educando se apresentam numa relação de cumplicidade, de parceria de troca; entendida como uma forma de pensamento, como uma "ferramenta" cognitiva, como instrumento para a leitura do mundo e que, muitas vezes, depende de outras áreas do conhecimento, que o processo de aquisição de conhecimentos não implicasse numa relação de dominação, mas numa base constante de novos desafios, com base na pesquisa, na reconstrução e, principalmente, na compreensão (RUIZ e GOMES, 1998, p.31).

Portanto, leitura e interpretação são partes fundamentais em um problema. Sem saber interpretar o que se pede não é possível seguir em frente. As dificuldades que os alunos apresentaram na interpretação dos enunciados devem-se à falta de vocabulário geral e também a não compreensão dos conceitos matemáticos envolvidos. Estas dificuldades condicionam a tradução da linguagem natural para a linguagem algébrica. Segundo Fonseca e Cardoso (2005):

\begin{abstract}
Parece-nos urgente que professores, pesquisadores e formadores dirijam suas atenções para o delicado processo de desenvolvimento de estratégias de leitura para 0 acesso a gêneros textuais próprios da atividade matemática escolar. A leitura e a produção de enunciados de problemas, instrução de propriedades, teoremas [...] demandam e merecem investigação e ações pedagógicas específicas que contemplem 0 desenvolvimento de estratégias de leitura, a análise de estilos, a discussão de conceitos de acesso aos termos envolvidos, trabalho esse que educador matemático precisa reconhecer e assumir como de sua responsabilidade (FONSECA e CARDOSO, 2005, p. 64-65).
\end{abstract}

As atividades mostradas no quadro 1 foram feitas e elaboradas pelas bolsistas do projeto, e a maioria delas teve como objetivo o aperfeiçoamento da aprendizagem, a utilização do raciocínio lógico-matemático e o trabalho do cálculo mental.

Quadro 1: Desempenho individual de cada aluno no decorrer do projeto. 


\begin{tabular}{|c|c|c|c|c|c|c|c|c|c|c|c|c|c|}
\hline Alunos & At.1 & At.2 & At.3 & At.4 & At.5 & At.6 & At.7 & At.8 & At.9 & At.10 & At.11 & At.12 & At.13 \\
\hline 1 & 100 & 100 & $\mathrm{~F}$ & 100 & 80 & 71 & $F$ & $\mathrm{~F}$ & 98 & 100 & 100 & $F$ & 100 \\
\hline 2 & 100 & 100 & $F$ & 100 & 90 & $F$ & 95 & 95 & 100 & 100 & $F$ & 90 & 100 \\
\hline 3 & $F$ & $\bar{F}$ & 100 & 100 & 95 & 100 & 100 & 90 & 100 & 90 & $F$ & 90 & 100 \\
\hline 4 & $F$ & $F$ & 100 & 100 & 70 & 80 & 75 & 78 & 98 & 98 & 90 & 100 & 100 \\
\hline 5 & 100 & 98 & $F$ & 100 & 98 & 100 & 88 & $F$ & 98 & $F$ & 98 & 100 & $\mathrm{~F}$ \\
\hline 6 & 100 & 100 & 98 & $F$ & 100 & 90 & 90 & $\mathrm{~F}$ & 100 & 100 & 95 & $\mathrm{~F}$ & 100 \\
\hline 7 & $F$ & 100 & $F$ & 100 & 100 & $F$ & 96 & 80 & 100 & 80 & $F$ & 85 & 100 \\
\hline 8 & $F$ & 100 & $F$ & 100 & 95 & 96 & 90 & $F$ & 98 & $F$ & 100 & 85 & $\mathrm{~F}$ \\
\hline 9 & $F$ & 100 & 80 & 100 & 80 & 75 & 80 & 98 & $F$ & 98 & 100 & 95 & 100 \\
\hline 10 & $F$ & $F$ & 98 & 100 & 98 & 96 & 100 & 80 & 100 & 98 & $F$ & 100 & 100 \\
\hline 11 & 100 & $F$ & 70 & $F$ & 98 & 98 & $F$ & $F$ & 98 & 95 & 100 & 100 & 100 \\
\hline 12 & 100 & 100 & $F$ & 100 & 95 & $F$ & 100 & 90 & 100 & $F$ & 100 & 100 & $\mathrm{~F}$ \\
\hline 13 & 100 & 100 & $F$ & 100 & 100 & 100 & $F$ & 86 & $\bar{F}$ & 100 & 90 & 90 & 100 \\
\hline 14 & 100 & $F$ & 80 & 100 & 100 & $F$ & 100 & $F$ & 98 & 100 & 98 & $F$ & 100 \\
\hline 15 & 100 & $F$ & 86 & 100 & $F$ & 90 & 100 & 92 & $F$ & 90 & 100 & $F$ & $F$ \\
\hline 16 & 100 & 100 & 95 & $F$ & $\mathrm{~F}$ & 88 & $\mathrm{~F}$ & $F$ & 100 & $F$ & 100 & $\mathrm{~F}$ & 100 \\
\hline 17 & 100 & 100 & 98 & 100 & $F$ & $F$ & $F$ & $F$ & 100 & 98 & 100 & $F$ & $F$ \\
\hline
\end{tabular}

Fonte: As autoras.

No quadro 1 são apresentadas as atividades desenvolvidas, conforme os códigos a seguir:

At 1 = Dança da cadeira, jogo da memória adição e subtração. At 2 = Problemas, desafios. At $3=$ Expressões numéricas. At $4=$ Filme, antecessor, sucessor. At 5 = Polígonos. At $6=$ Equações. At $7=$ Potências. At $8=$ Unidades de medidas. At $9=$ Gincana. At $10=$ Plano cartesiano. At $11=$ Geogebra. At $12=$ Porcentagem. At 13 = Área, Perímetro.

Os vídeos escolhidos foram os relacionados aos temas de cidadania e às quatro operações, de forma a incluir as questões sociais e as diferenças locais em que os alunos estão inseridos, enriquecendo e melhorando as atitudes dos mesmos, uma vez que a rotina destes alunos é de turno integral nas escolas, convivendo apenas o período noturno em suas casas, com suas famílias. Deste modo, eles foram escolhidos por um critério de necessidades comuns entre os alunos.

\section{CONCLUSÃO}


Após o término do projeto, a partir da coleta de dados, da evolução dos alunos e do questionário pessoal feito com a turma, pode-se concluir que o uso das atividades lúdicas no espaço escolar permitiu a construção do conhecimento matemático, visto que despertaram o interesse dos alunos para a disciplina, bem como os incentivou a pensar, analisar e fazer conjecturas. Entretanto, é necessário que a utilização de jogos, softwares, vídeos e materiais manipulativos estejam relacionados aos fundamentos pedagógicos para que aconteça a aprendizagem na Matemática.

Um dos grandes problemas de aprendizagem dos alunos foi a dificuldade de interpretar textos e saber transpor para uma linguagem matemática. A experiência docente para as bolsistas mostrou que dado um exercício matemático que requer leitura e interpretação do problema, em questão de segundos a maioria dos alunos reclamaram que não entenderam.

As atividades com os jogos e os materiais manipulativos envolveram expressões numéricas, probleminhas e jogos com as quatro operações. Com essa prática, as atividades não se tornaram monótonas e os alunos, na medida do possível, interessavam-se, compreendiam, interagiam e resolviam as atividades propostas com facilidade.

As atividades com os vídeos despertaram o interesse e a socialização entre os alunos. Eles assistiram aos vídeos, contaram fatos que presenciaram ou vivenciaram e também desenharam e escreveram redações referentes aos temas abordados, movimentando o grupo.

A realização deste projeto teve uma grande contribuição para a formação dos acadêmicos bolsistas, levando-os a refletir sobre a prática docente, as aprendizagens dos alunos participantes do projeto e as próprias aprendizagens. De uma maneira geral, levou-os a reforçar a ideia de que o ensino deve ser reflexivo e dinâmico, com metodologias alternativas que proporcionem ao aluno pensar e conjecturar.

\section{REFERÊNCIAS}

CIAEM. Concluintes das séries iniciais do ensino fundamental da EJA e problemas matemáticos escolares. Disponível em:

<http://www.gente.eti.br/lematec/CDS/XIIICIAEM/artigos/1050.pdf>. Acesso em: 20 nov. 2015. 
CIAEM. Concluintes da primeira etapa do ensino fundamental no sistema de educação de jovens e adultos (EJA) e problemas matemáticos escolares.

Disponível em: <http://www.unicentro.br/editora/anais/xeprem/CC/05.pdf>. Acesso em: 22 nov. 2015

FONSECA, Maria C. F. R.; CARDOSO, Cleusa de A. Educação matemática e letramento: textos para ensinar matemática, matemática para ler texto. In: NACARATO, A. M.; LOPES, C. E. (org). Escritas e Leituras na Educação Matemática. Belo Horizonte: Autêntica, 2005. p.63-76. GÓMES-GRANELL. LUCKESI, Cipriano Carlos. Avaliação da aprendizagem escolar. 19. ed. São Paulo: Cortez, 2015.

RUIZ, Adriano R.; GOMES, Maristela G. Solução de problemas de matemática: procedimentos utilizados por sujeitos com graus de escolaridade diferentes. Dissertação de Mestrado (Educação na Área de Concentração: Psicologia Educacional), Faculdade de Educação da Universidade Estadual de Campinas, 1998.

SILVA, Carla Priscila Alves da. O reforço escolar e a melhoria da aprendizagem dos educandos. Disponível em: <http://www.artigonal.com/educacao-infantilartigos/o-reforcoescolar-e-a-melhoria-da-aprendizagem-dos-educandos1290785.html>. Acesso em: 14 nov. 2015. 